\title{
A Study on Harmonics in Indian Railway Traction
}

\author{
N.Gunavardhini ${ }^{1}$, M.Chandrasekaran ${ }^{2}$ A.D.Thirumoorthy ${ }^{3}$ \\ ${ }^{1}$ (Asst. Executive Engineer, Tamil Nadu Electricity Board, Salem, India) \\ ${ }_{2}^{2}$ (Head/Electronics \& Communication Engineering, Government College of Engineering, Salem, India) \\ ${ }^{3}$ (Superintending Engineer, Tamil Nadu Electricity Board, Coimbatore, India)
}

\begin{abstract}
The power quality is being affected by the railway traction load. Its effects on power quality cannot be ignored. Hence, a study was done in two traction sub-stations. In this, two railway traction sub-stations were taken for case study. One is Salem 110KV Railway traction where 2400 KVAR rated capacitor bank alone is installed and another is Bommidi $110 \mathrm{KV}$ Railway traction where IGBT based Dynamic Reactive Power Compensation (DRPC) with 1800 KVAR is connected along with fixed 240OKVAR capacitor bank. Both these traction points are nearby and are in the same railway divisions. By installing power quality monitoring system in the sub-station supplying traction load directly, the actual operation data of this traction power supply is obtained. The harmonics due to load currents are measured and compared in both the sub-stations based on IEEE Standards 519-1992.
\end{abstract}

Keywords: DRPC, Harmonics, Power Quality, Traction Load characteristics, Traction Station

\section{Introduction}

The electrified railway is considered to be an important environment friendly transport way because of it is high speed and remarkable transportation capability with great efficiency. According to the "long term integrated transport network development plan" issued by National Development and Reform Commission, in order to meet the request of economic development, country will promote the high speed electrified railway constructions to improve the railway transportation capability [1].

Compared to the conventional electrified railway [2], the high-speed electrified railway has a higher density traffic, which needs a more reliable and large traction power. The large impactive traction loads calls for a strong power supply system. Compared to the conventional electrified railway traction load, the high speed electrified railway traction load's effects have new characteristics, such as having negative sequence current and less harmonics.

The Salem traction station and Bommidi traction stations are at a distance of $65 \mathrm{~km}$ and the loads are same on both the stations and both are in the same railway division. DRPC is installed in Bommidi traction in addition to the fixed capacitor which was commissioned during 1991 where as at Salem traction only capacitor bank is installed. As per EN 51000 standards, Harmonics are measured in both the traction sub-stations.

In Section-II, it was discussed about the power supply system, power characteristics and transaction load, and current characteristics of traction load [3].

In Section-III, harmonics of both the traction sub-stations were studied and compared as per IEEE Standards 519-1992 [4]

\section{Traction load characteristics}

\subsection{Brief introduction of power supply system}

The high-speed electrified railway call for a power supply system with large short-current capacity[5]. The traction network can be integrated into the power supply system via single phase transformers. V/v connected transformers or balance transformers and single phase transformers are always adopted[3].

A typical $110 \mathrm{KV}$ single phase Indian Railway traction power supply system is shown in Fig.1. The two single phase traction transformers are integrated into the power supply system by connecting their primary coils between Phase A and B of line A and Line B. At normal operation mode, one traction transformer is supplying power and the other one is standby. One terminal of the traction transformer's $25 \mathrm{KV}$ secondary coil connected to earth and the other one is splitting to line $\mathrm{T}$ and Line $\mathrm{F}$. Usually, the line $\mathrm{T}$ is supplying traction power for the train and Line $\mathrm{F}$ is standby.

The traction sub-station can be considered to a source of negative sequence current and harmonic current. 


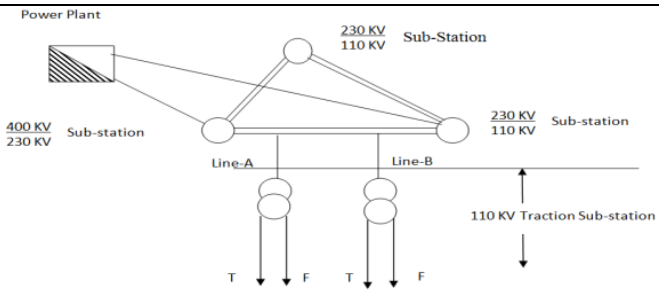

25 KV Traction Network

figure 1 A traction Load Power System Supply System

\subsection{Power Characteristics of Traction Load}

The traction load of the traction substation is the traction power for trains running on this railway section. Usually, trains work in three typical situations: accelerating to start up, running at an invariable speed or decelerating to break down [3].

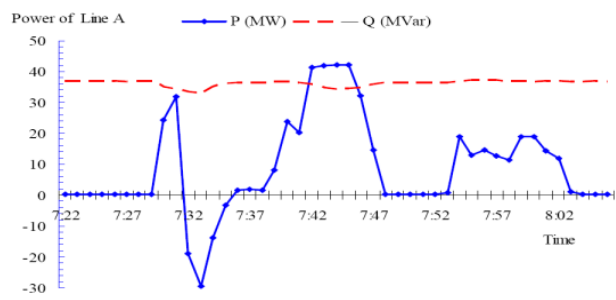

figure 2. Load curve of the traction [3]

The operating data showed in Fig.2 is the transmission power on line A. The active power fluctuates along with the traffic situation, when the train starts up there is a significant accelerating traction power and when the train is brakes down there is even a negative decelerating traction power. The power reactive power is mostly generated by the power transmission cable's distributed capacitance, which is not independent of the traffic situation.

Because the active power load of the traction substation is not independent of the traffic situation such as traffic density, the traction load will fluctuate continually.

\subsection{Current Characteristics of Traction Load}

At a normal operation mode, line A supplies the traction load. Considering that $110 \mathrm{KV}$ power transmission cable's distributed capacitance to the earth is large, and the distributed capacitance of $25 \mathrm{kV}$ traction network also can't be ignored, the traction power supply system can be equaled to the simplified model described in Fig.3 [3].
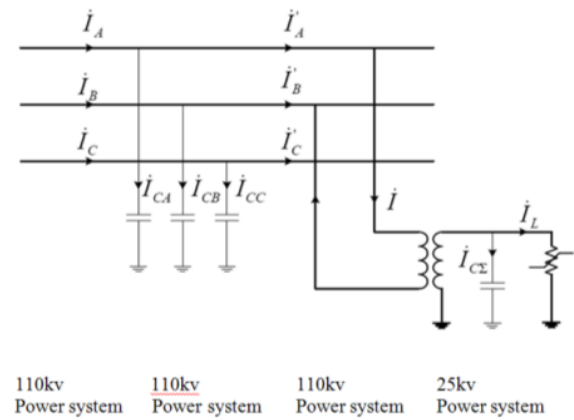

figure 3. Equivalent model of traction power supply system [3]

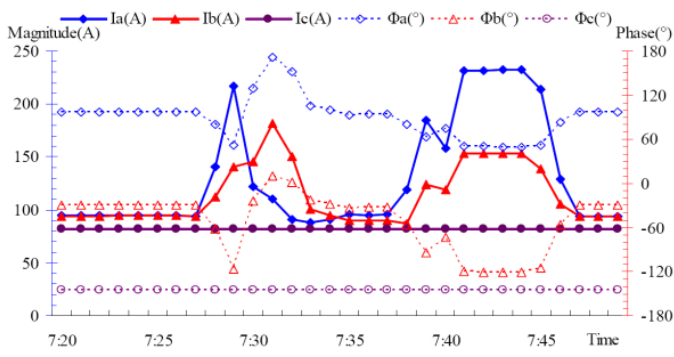

figure 4. Load current of the train [3] 
Fig. 4 shows the load current of line A during the process that a train enters the supplying section, brake down and starts up again, the working situation just accords with the simplified model described in Fig.3. The capacitive current of Phase C is about 80A and the traction current of Phase A or Phase B is about 150A-200A, the current unbalanced factor will be significant.

\section{Study of harmonics}

The harmonics were measured in two traction sub-stations by installing harmonic analyzer as per EN 51000 directly on load point as in Fig.5. The voltage and current harmonics varies according to load current and the characteristics are as in Fig. 6 to Fig. 11.

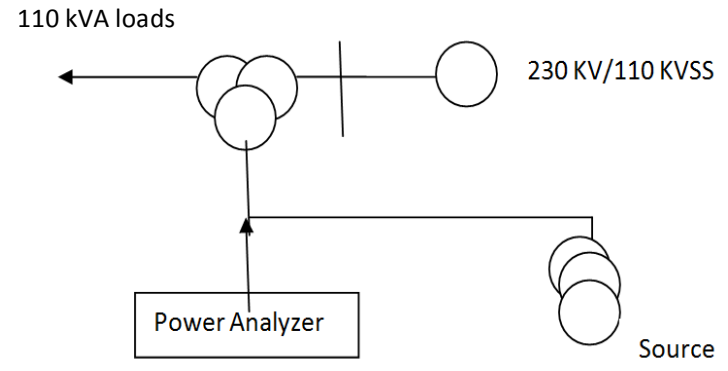

figure 5. Measuring Method

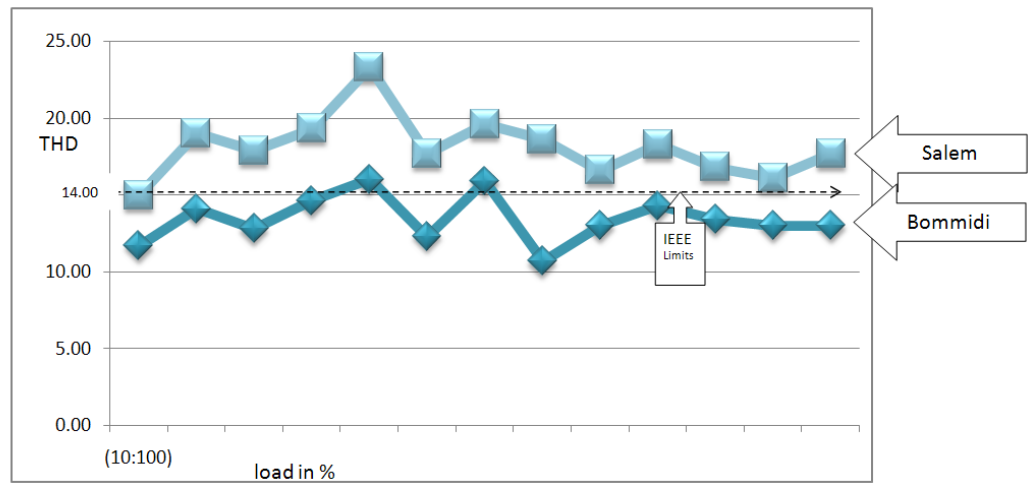

figure 6 Current Total Harmonic Distortion at Salem \& Bommidi Tractions

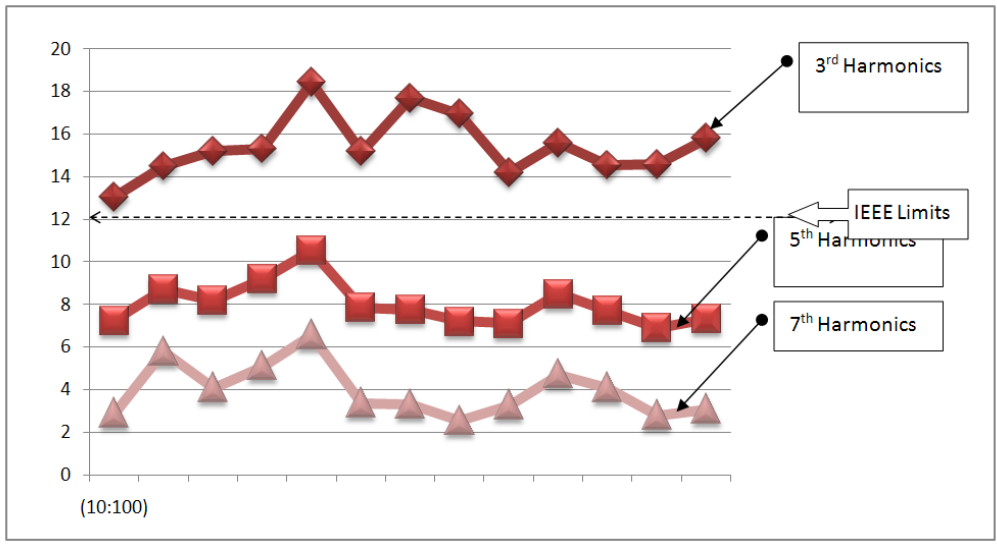

figure 7 Current Harmonic at Salem Traction 


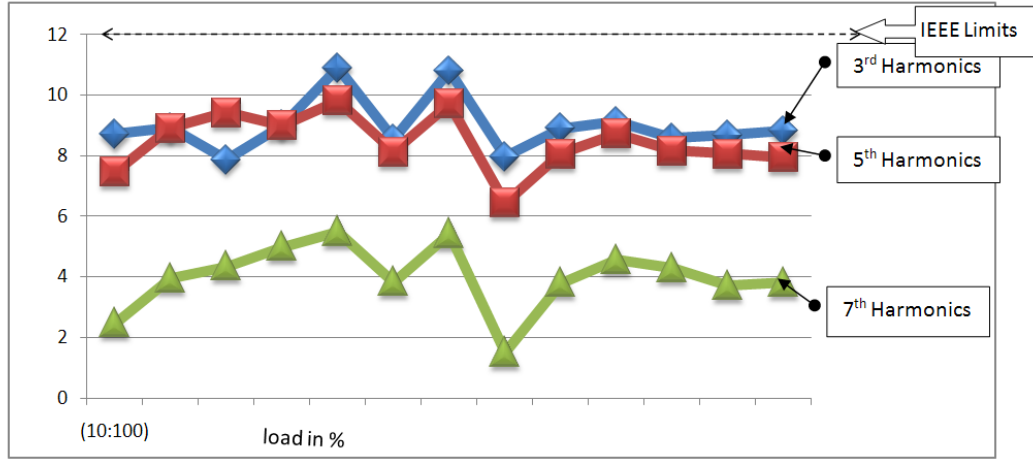

figure 8 Current Harmonic at Bommidi Traction

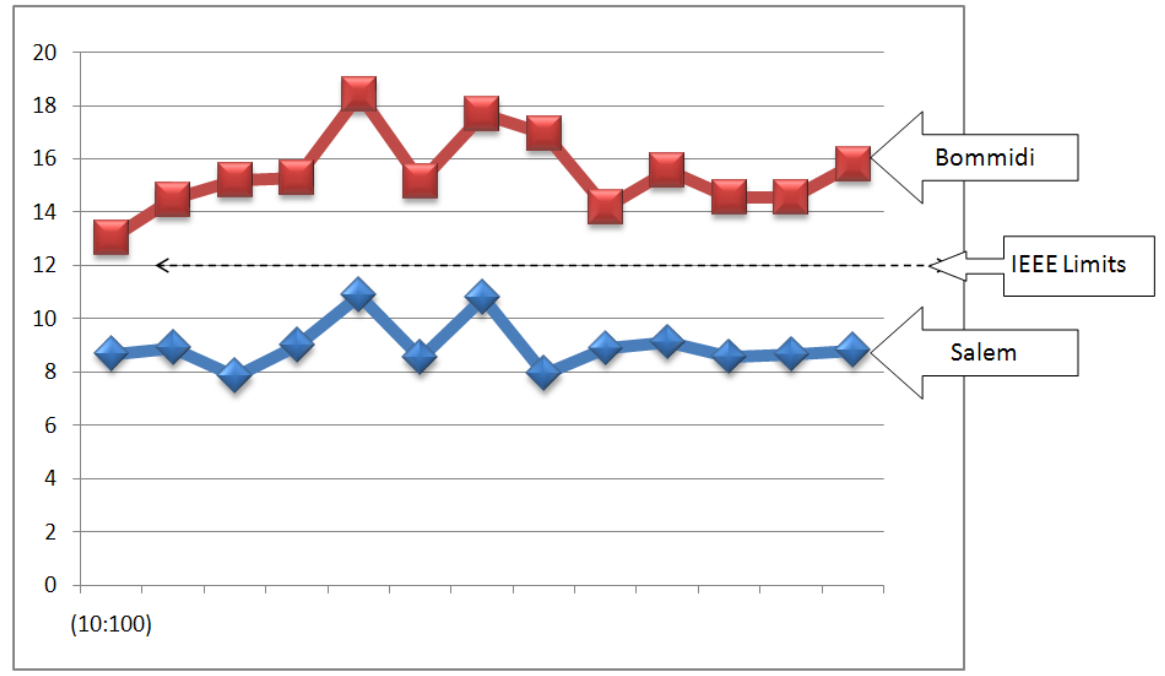

figure $93^{\text {rd }}$ Current Harmonic at Bommidi \& Salem Tractions

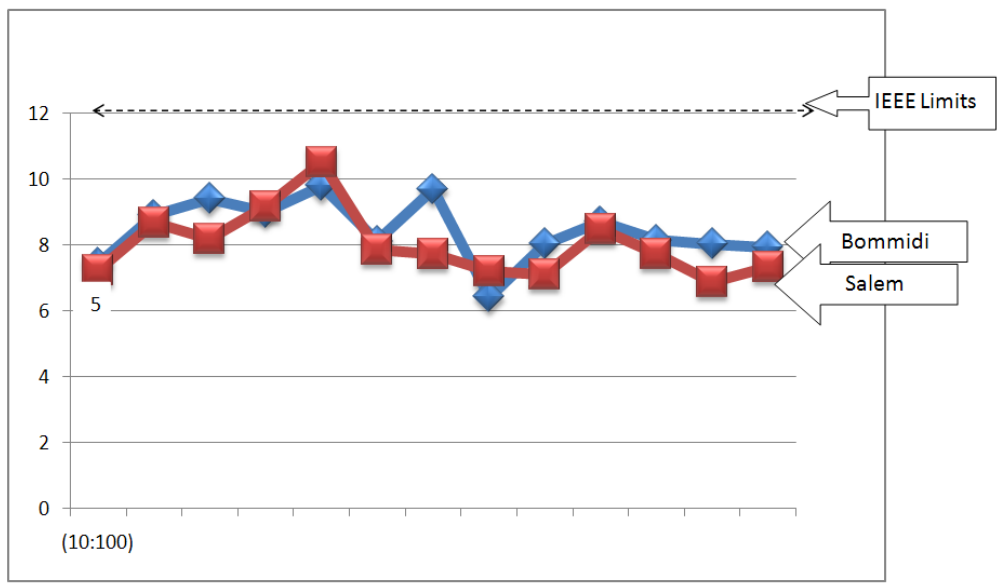

figure $105^{\text {th }}$ Current Harmonic at Bommidi \& Salem Tractions 


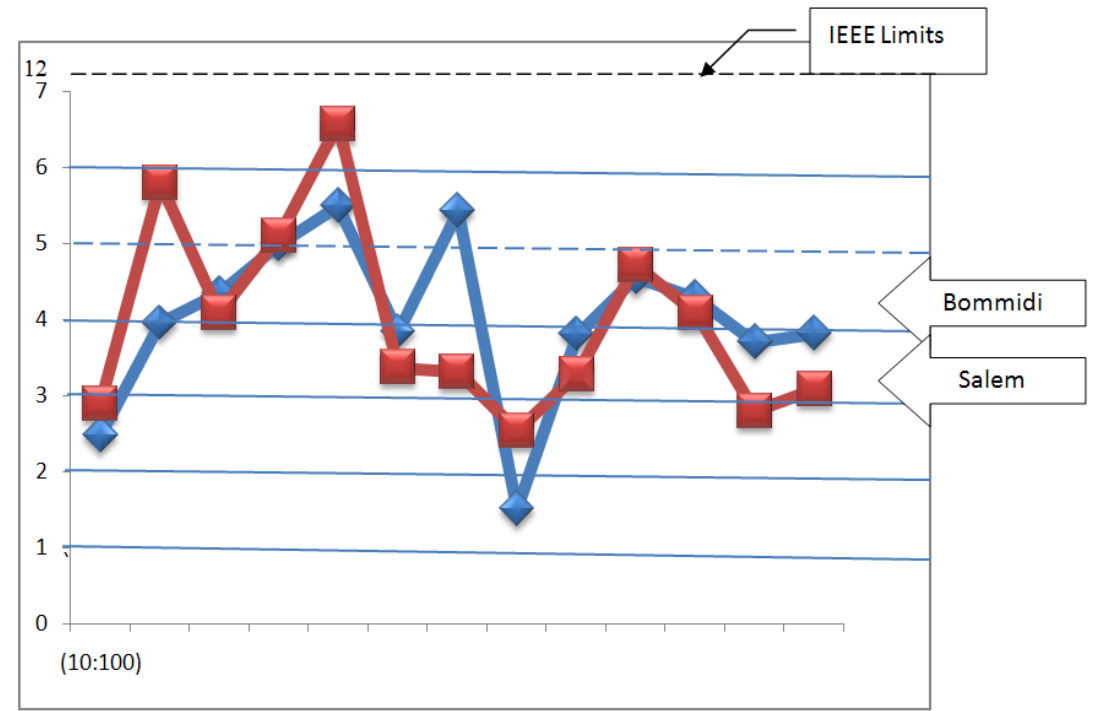

figure $117^{\text {th }}$ Current Harmonic at Bommidi \& Salem Tractions

IV.

Conclusion:

According to the analysis, the harmonics at Salem traction is very much higher than Bommidi traction. In spite of the presence of DRPC in the Bommidi traction which cost around 2 crores, the current THD are not within the IEEE limits and is very much higher in Salem traction.

The railway traction load impacts and contains harmonics and negative sequence current, which will worsen the power quality of general power system.

Analysis and improvements of power quality based on the harmonics will be scope of another paper.

\section{References}

[1] National Development Reform Commission Long Term Integrated Network Development Plan (Z) 2007.

[2] Li Qunzhan. On Some Technical Key Problems in the Development of Traction Power Supply System for high speed railway in China (J) Journal of the China Railway Society, 2010, 32(4): 119-124

[3] Liu Yu-Quan "Research for the effects of high speed electrified Railway Traction Load on Power Quality - IEEE - 2012

[4] IEEE Standards 519-1992.

[5] ZHANG Xiaoyu, WU Junyong, "Research on Voltage Class of Power System to be connected with Electrified Railways (J) Power System Technology, 2007, 31(1): 12-17. 